\title{
Grading System Based on Intra Operative Findings at Laparoscopic Cholecystectomy
}

\author{
Brajesh Kumar $^{1}$, Saurov Ghose ${ }^{1}$, Vipul Krishan Sharma ${ }^{2}$, Manashi Ghosh ${ }^{3, *}$ \\ ${ }^{1}$ Department of Surgery, Military Hospital, Dehradun, India \\ ${ }^{2}$ Department of Anesthesia, Military Hospital, Dehradun, India \\ ${ }^{3}$ Department of Radiotherapy, Govt Doon Medical College, Dehradun, India
}

Email address:

ghoshmanashi4@gmail.com (M. Ghosh)

${ }^{*}$ Corresponding author

\section{To cite this article:}

Brajesh Kumar, Saurov Ghose, Vipul Krishan Sharma, Manashi Ghosh. Grading System Based on Intra Operative Findings at Laparoscopic Cholecystectomy. Journal of Surgery. Vol. 6, No. 5, 2018, pp. 123-128. doi: 10.11648/j.js.20180605.13

Received: August 15, 2018; Accepted: September 1, 2018; Published: September 19, 2018

\begin{abstract}
Laparoscopic Cholecystectomy has become the standard of care for Gall Stone Disease. There are numerous studies and scoring system which considers the pre-operative factors for conversion to open cholecystectomy but there was no scoring system which considers intra operative findings. The objective of this study was to outline the scoring system based on intra operative findings to predict the conversion of laparoscopic cholecystectomy to open cholecystectomy. This prospective study was carried out on 158 patients who underwent cholecystectomy. Surgery in all patients were started with laparoscopic cholecystectomy and based on multiple factors the surgery was completed as open or laparoscopic cholecystectomy. Based on the intra operative findings the patients were divided into easy, moderate, very difficult and extreme. The patients with severe and extreme scoring had highest number of conversions to open cholecystectomy and those patients who had total score of less than 5 had negligible conversion to open cholecystectomy. This paper reports the scoring system which considers the intra operative findings during laparoscopic cholecystectomy. Based on this scoring system it can be predicted weather conversion to open cholecystectomy is required or not.
\end{abstract}

Keywords: Laparoscopic Cholecystectomy, Open Cholecystectomy, Grading System, Intra Operative Findings, Pre-Operative Findings

\section{Introduction}

Laparoscopic Cholecystectomy has become increasingly common since 1980 and has replaced open cholecystectomy as the standard of care $[1,2]$. The laparoscopic approach causes less mortality and morbidity compared to conventional cholecystectomy. It also offers the advantage of being minimal invasive, less hospital stays, less post-operative pain and early recovery [3-5].

Management of cholelithiasis has seen a shift from conventional open cholecystectomy to laparoscopic cholecystectomy [6-8]. Sometimes lap cholecystectomy becomes difficult and it takes longer time specially with bile /stone spillage and may require conversion to open cholecystectomy [8-11]. It has been seen that surgeons face difficulty during laparoscopic surgery when there are dense adhesions at Calot's triangle, fibrotic or contracted bladder [12]. Hence conversion to open cholecystectomy would always be considered as the part of safe surgical practise but a detailed understanding of the factors leading to conversion is important.

There are numerous studies and scoring system which considers the pre operative factors for conversion to open cholecystectomy but there was no scoring system which considers intra operative findings [12-19]. Recently a new scoring system has been formulated which grades the intra operative findings during laparoscopic cholecystectomy and based on the final score, it is predicted whether the patient would require conversion to open cholecystectomy [20]. This study aims to formulize a scoring system considering various operative findings at laparoscopic cholecystectomy. 


\section{Methods}

This non-randomized study was carried out prospectively on 158 patients with symptomatic cholelithiasis who underwent cholecystectomy between Jan 2017 to June 2018 at Military Hospital Dehradun. All the surgeries were performed by two surgeons, hence there was not much variations in the expertise available. Surgery on all patients was started with Laparoscopic cholecystectomy and subsequently based on the intra operative findings and difficulties, surgery was converted to open cholecystectomy or completed as laparoscopic cholecystectomy. All operations were performed under general anaesthesia.

Five key aspects considered in this study was as follows:
(1) Ease of access.

(2) Appearance of gall bladder and amount of adhesions.

(3) Degree of contraction/distension of gall bladder.

(4) Local/septic complications.

(5) Time taken to identify cystic artery and duct.

Exclusion Criteria's

(1) Patients with acute cholecystitis were excluded from the study.

(2) Laparoscopic cholecystectomy combined with some other procedure.

(3) Laparoscopic cholecystectomy with CBD exploration.

(4) Complication of laparoscopic cholecystectomy in form of CBD injury recognised pre-operatively.

The details of scoring system are given in Table 1 .

Table 1. Factors considered for Intra operative Grading System.

\begin{tabular}{lll}
\hline Details of patient & Name & Age/Sex \\
\hline Predictors & Points \\
\hline Gall Bladder Appearance: & 0 \\
No adhesions & 1 \\
Adhesions $<50 \%$ of Gall Bladder- & 3 \\
Adhesions Burying GB- & \\
Distension/Contraction: & 1 \\
Distended GB or Shriveled GB & 1 \\
Unable to Grasp with Atraumatic Laparoscopic Forceps & 1 \\
Stone $>1$ cm Impacted at Hartman's Pouch & \\
Access: & 1 \\
BMI $>30$ & 1 \\
Adhesions from previous surgery limiting Access & \\
Severe sepsis/Complication: & 1 \\
Bile or Pus outside GB & 1 \\
Time to identify Cystic artery and Duct $>90$ min & \\
Total Points & \\
\hline
\end{tabular}

Degree of Difficulty: Mild/ Moderate/Severe/Extreme

(Mild<2, Moderate 2-4, Severe 5-7, Extreme 8-10)

\section{Results}

The scoring system is based on severity of cholecystitis and grades of potential difficulty with total score ranging from 1 to 10. The various factors which are considered are difficulty in access to gall bladder, degree of pericholic and surrounding adhesions, the presence or absence of complicated cholecystitis and time taken to identify cystic artery and cystic duct. The total score of less than 2 was considered as easy with no potential to conversion to open cholecystectomy. The score of 2-4 was considered moderate difficulty, 5-7 severe difficulty and a score of 8 or more was considered extremely difficult with highest rate of conversion to open cholecystectomy.

Age distribution: In the present study patients were of from the age group 20 years and above. The youngest patient was of age 21 years and oldest was 78 years.

Table 2. Age distribution.

\begin{tabular}{lll}
\hline Age group & No of patients & Percent $(\%)$ \\
\hline $20-30$ & 21 & 13.29 \\
$30-40$ & 40 & 25.31 \\
$>40$ & 97 & 61.39 \\
Total patients & 158 & \\
\hline
\end{tabular}

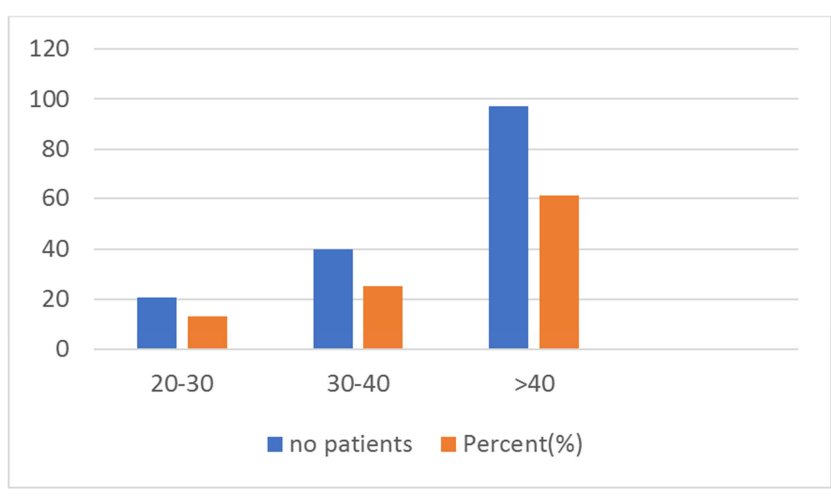

Figure 1. Age Distribution.

Sex distribution: Out of 158 patients taken in this study 131 were female as compared to only 27 males.

Table 3. Sex distribution.

\begin{tabular}{lll}
\hline Sex & No of patients & Percent $(\%)$ \\
\hline Male & 27 & 17.08 \\
Female & 131 & 82.91 \\
Total patients & 158 & \\
\hline
\end{tabular}




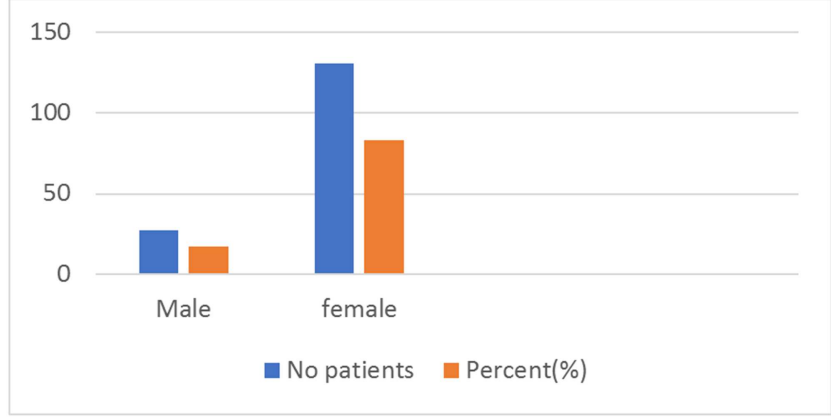

Figure 2. Sex Distribution.

Gall Bladder appearance: Of all the patients under study 76 patient had less than 50 percent adhesions while 68 patients had more than 50 percent adhesions. In 14 patients Gall bladder was buried under omental adhesions.

Table 4. Gall Bladder appearance.

\begin{tabular}{lll}
\hline Adhesions over Gall Bladder & Number & Percent (\%) \\
\hline$<50$ percent & 76 & 48.10 \\
$>50$ percent & 68 & 43.03 \\
Buried Gall Bladder & 14 & 08.86 \\
\hline
\end{tabular}

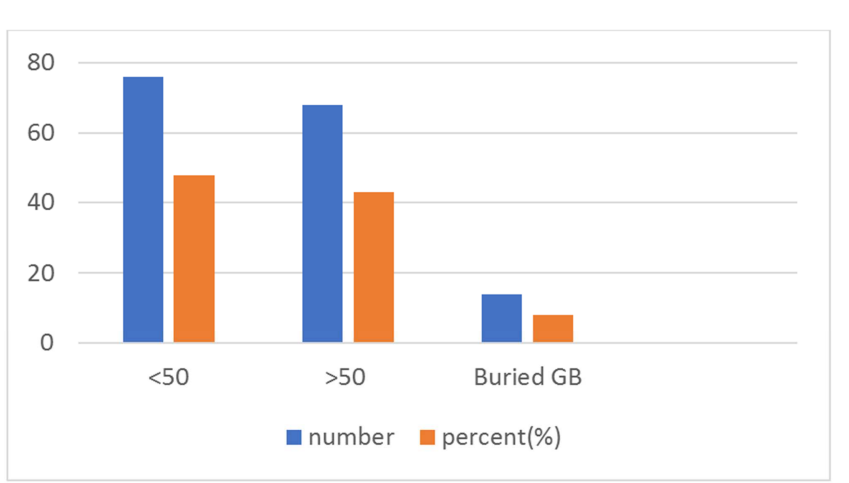

Figure 3. GB Adhesions.

Distended/contracted Gall Bladder: In this study 143 patients had distended Gall Bladder while 15 patients had contracted Gall Bladder.

Table 5. GB appearance.

\begin{tabular}{lll}
\hline GB appearance & Number & Percent (\%) \\
\hline Distended & 143 & 90.50 \\
Contracted & 15 & 09.50 \\
\hline
\end{tabular}

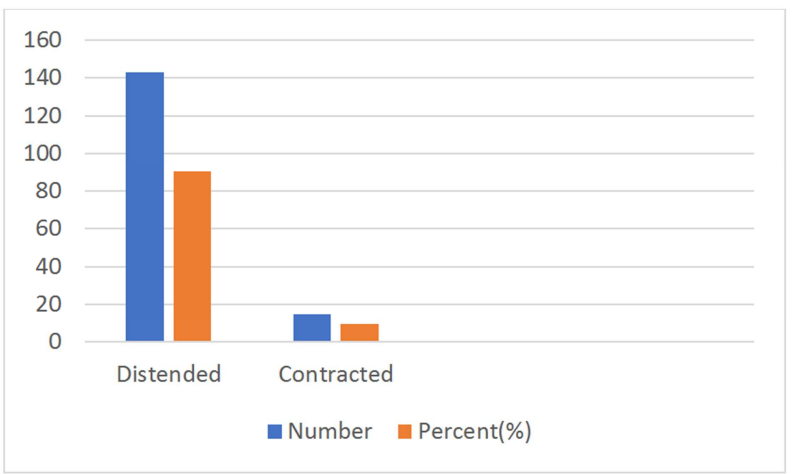

Figure 4. GB Appearance.
Grasping with Atraumatic Forceps: There were 136 patients where surgeon was able to hold gall bladder with atraumatic forceps while in rest it was not possible.

Table 6. Grasping with atraumatic forceps.

\begin{tabular}{lll}
\hline $\begin{array}{l}\text { Grasping with Atraumatic } \\
\text { forceps }\end{array}$ & Number & Percent (\%) \\
\hline Possible & 136 & 86.07 \\
Not possible & 22 & 13.92 \\
\hline
\end{tabular}

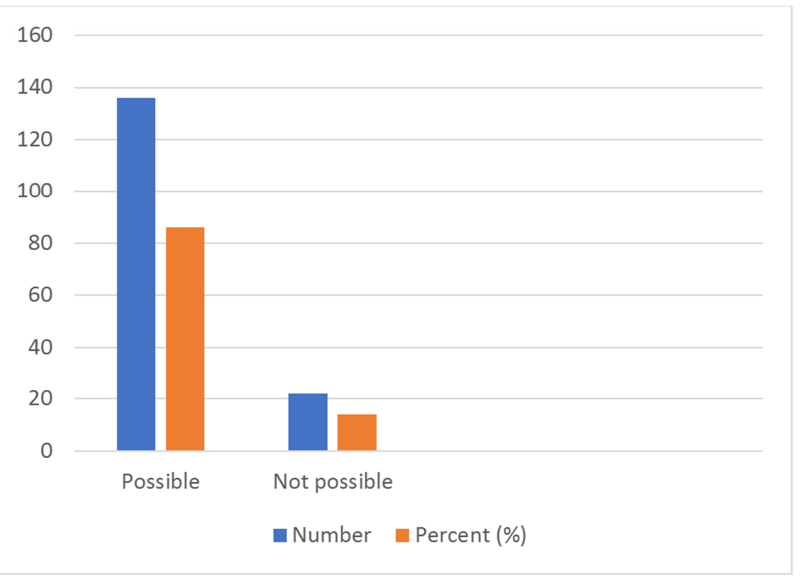

Figure 5. Grasping with Atraumatic Forceps.

Stone $>1 \mathrm{~cm}$ Impacted in Hartmann's Pouch: Of all the patients in this study only 6 had stone impacted at Hartmann's Pouch while rest had no stones at Hartmann's pouch.

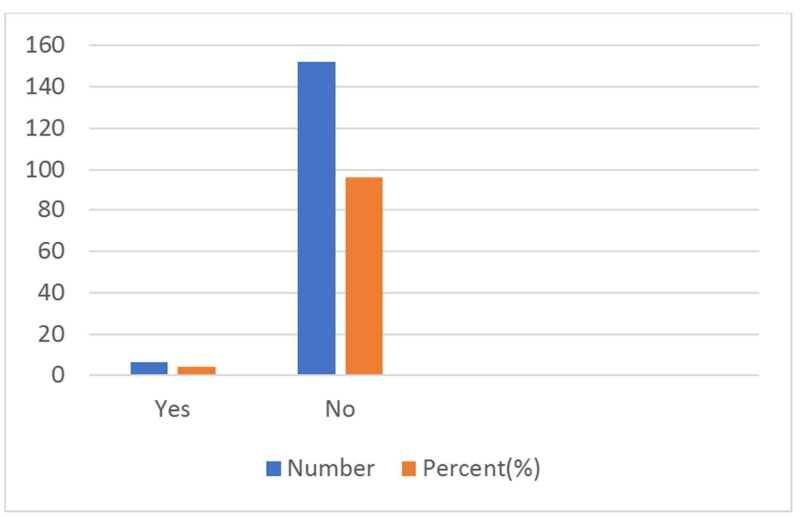

Figure 6. Stone $>1 \mathrm{~cm}$ impacted at Hartmann's Puoch.

Table 7. Stone impacted at hartmann's pouch.

\begin{tabular}{lll}
\hline $\begin{array}{l}\text { Stone }>\mathbf{1} \mathbf{c m} \text { impacted at } \\
\text { Hartmann's Pouch }\end{array}$ & Number & Percent (\%) \\
\hline Yes & 6 & 3.80 \\
No & 152 & 96.20 \\
\hline
\end{tabular}

Body Mass Index (BMI): - 102 patients in this study had $\mathrm{BMI}<30$ while 56 had $\mathrm{BMI}>30$.

Table 8. BMI.

\begin{tabular}{lll}
\hline BMI & Numbers & Percent (\%) \\
\hline$<30$ & 102 & 64.55 \\
$>30$ & 56 & 35.45 \\
\hline
\end{tabular}




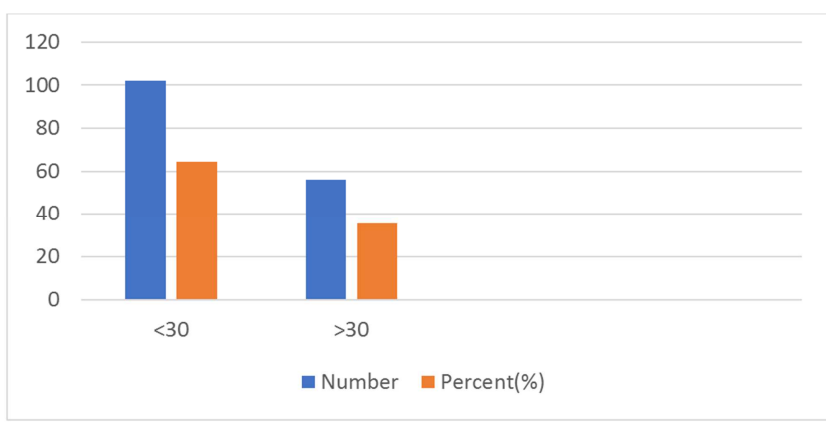

Figure 7. BMI.

Adhesions from previous surgery limiting Access: - In this study total 8 patients had adhesions from previous surgeries which limited the access to the Calot's triangle and Gall bladder causing difficulties in dissection while others had no such adhesions.

Table 9. Adhesions from previous surgery.

\begin{tabular}{lll}
\hline Adhesions & Number & Percent (\%) \\
\hline Present & 8 & 5.06 \\
Absent & 150 & 94.9 \\
\hline
\end{tabular}

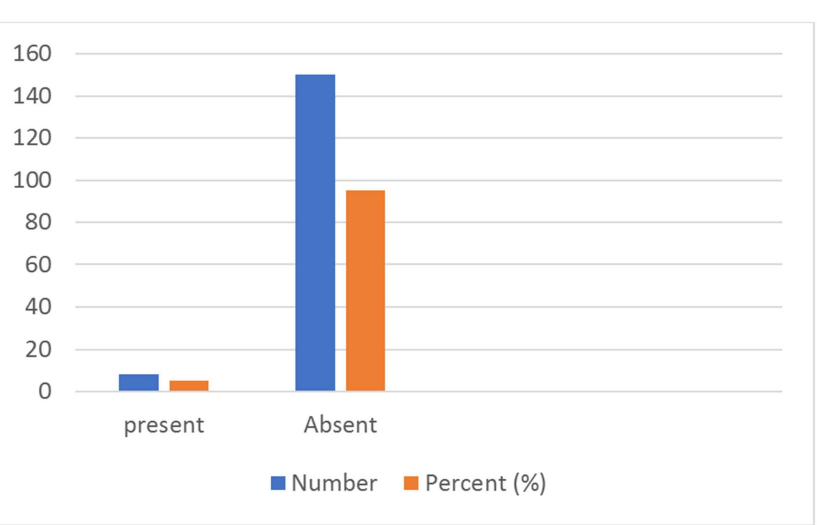

Figure 8. Adhesions from Previous surgery.

Bile/pus leak from Gall Bladder: - In this study there were total 16 patient who had bile or pus leak from gall bladder per operatively, while rest had no such leak.

Table 10. Bile/Pus leak from GB.

\begin{tabular}{lll}
\hline Bile/pus leak from GB & Number & Percent (\%) \\
\hline Present & 16 & 10.12 \\
Absent & 142 & 89.88 \\
\hline
\end{tabular}

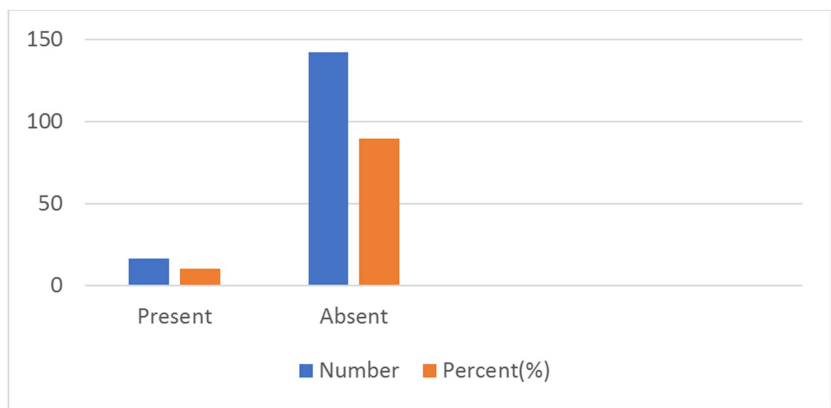

Figure 9. Bile/Pus Leak from $G B$.

Time taken to identify cystic artery and Duct: - in our study there were 137 patients in whom total time for identifying and dissecting cystic duct and artery was less than 90 min while in rest of patients the time taken was more than 90 min because of incomplete visualization of Calot's triangle.

Table 11. Time taken to identify cystic duct and artery.

\begin{tabular}{lll}
\hline $\begin{array}{l}\text { Time taken to identify cystic } \\
\text { duct and artery }\end{array}$ & Number & Percent (\%) \\
\hline$<90 \mathrm{~min}$ & 137 & 86.70 \\
$>90 \mathrm{~min}$ & 21 & 13.30 \\
\hline
\end{tabular}

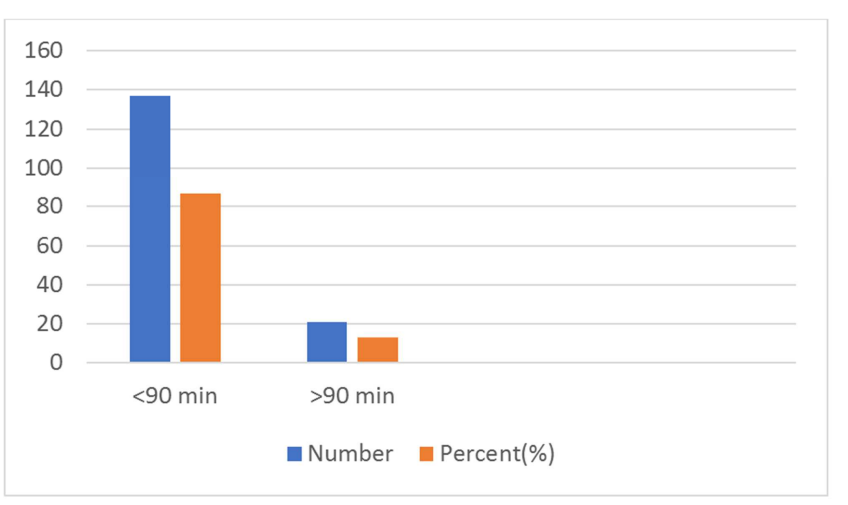

Figure 10. Time taken to identify cystic duct and artery.

Degree of difficulty:

In our study, for each patient, individual variables discussed above were added and a total score was calculated. Further based on total score all the patients were divided into four groups. They were graded into easy, moderate, very difficult and extreme difficulty group with corresponding total score $<2,2-4,5-7$ and 8-10. There were 43 and 76 patients in easy and moderate difficulty group respectively in which all the surgeries were completed with laparoscopic cholecystectomy. There were 28 patients in very difficult group in which 03 surgeries has to be converted to open cholecystectomy. There were 11 patients in extreme difficulty group out which 9 patients were converted to open cholecystectomy.

Table 12. Degree of difficulty.

\begin{tabular}{llll}
\hline Grading score & Number of patients & Open cholecystectomy done & Percent of open cholecystectomy \\
\hline Easy $<2$ & 43 & 00 & 00 \\
Moderate 2-4 & 76 & 00 & 00 \\
Very difficult 5-7 & 28 & 03 & 10.7 \\
Extreme $8-10$ & 11 & 09 & 81.8 \\
Total & 158 & 12 & 7.59 \\
\hline
\end{tabular}




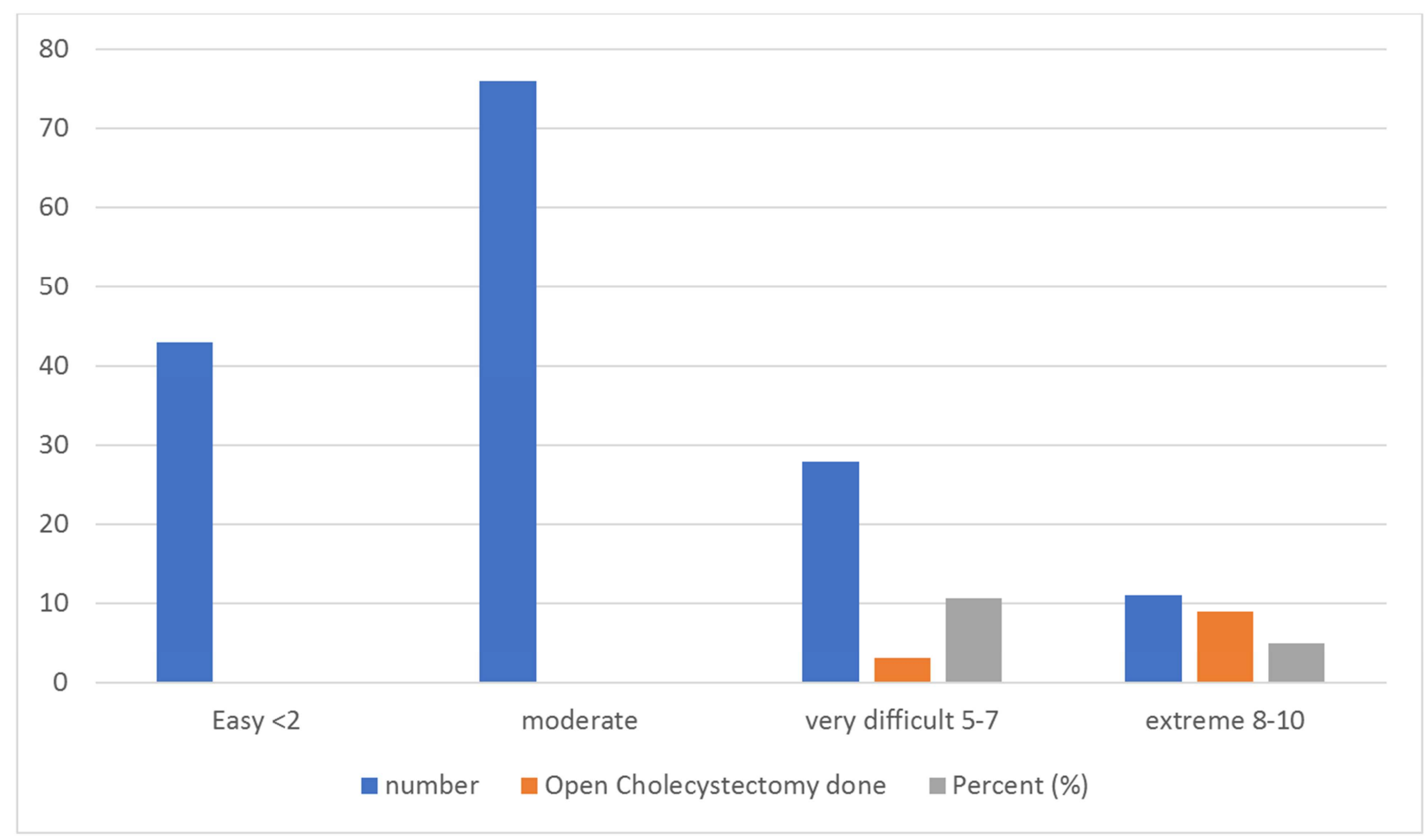

Figure 11. Degree of Difficulty.

\section{Discussion}

Symptomatic cholelithiasis is one of the most commonly encountered disease in outdoor setting as well as in hospital settings [21, 22]. Hence Cholecystectomy either open or laparoscopic is one of the most common surgery performed, with associated mortality of $0.45 \%$ to $6 \%$. Mortality depends on the severity of the disease, mode of presentation and time interval after which the patient presents to the physician [23]. Publications reporting outcomes, including conversion to open surgery, are hard to compare as there is no scoring or grading system of operative findings at surgery [24, 25].

Laparoscopic cholecystectomy has become the modality of choice for treatment of cholelithiasis. However, the complication rate and outcome are very variable depending on variable findings. Hence it is important that surgeons should realize that conversion to open cholecystectomy is neither the complication or failure but should be done for the patients safety. The various reasons for variations in outcome are probably surgeon's experience, disease severity and available instrumentation. However, there are many more factors which contribute to the variations in outcome. A hepatobiliary surgeon might take less time for completing the surgery and may have a lower conversion to open cholecystectomy compared to the general surgeon based on more experience and knowledge. However, comparison between surgeon, institution and published series are currently impossible as the denominator of the severity of cholecystitis is not standardized and has been rarely reported.

The various studies and articles published have given various grading system for potential for conversion to open cholecystectomy. Most of these studies have used the pre-operative factors based on USG and CT Scan findings and various other biochemical and clinical parameters. A scoring system has been given by Michael Sugre and et al [20] which used the various per operative findings for predicting conversion of lap cholecystectomy to open cholecystectomy. This scoring system uses various parameters like BMI, adhesions around Gall Bladder, distended/ shrivelled Gall Bladder, surrounding sepsis and time taken to identify Cystic duct and artery.

This study revealed that highest conversion rate was in the group of patients having extreme difficulty with total score between 8-10 (81.8\%). The conversion rate in moderate group was approx. $11 \%$. In the group of patients where total scoring was $<5$ the conversion rate to open cholecystectomy was zero percent.

There are certain limitations to the current scoring system. There is some subjectivity in the terms of presence and degree of adhesions around gall bladder. There are no objective criteria to determine in terms of degree of adhesions. Also, the kind of adhesions in terms of vascularity and tenacity differs in patients having same degree of adhesions around gall bladder. Another limitation is that it does not consider into account the degree of intra operative bleeding. The actual amount of bleeding is hard to define by objective criteria.

\section{Conclusion}

The current scoring is one of the few to outline key operative findings to predict conversion of laparoscopic to open cholecystectomy. This study shows that the patients having extreme or severe scoring based on per operative factors have the highest rate of conversion to open 
cholecystectomy. Those patients who have mild or moderate scoring have almost negligible or zero conversion rate to open cholecystectomy. Certain key points can be determined from this study which are follows:

(1) Adhesions from previous repeated episodes of acute/ chronic cholecystitis causes difficulties during the laparoscopic cholecystectomy.

(2) Patients who are obese or morbidly obese tend to have more conversion rate to open cholecystectomy because of difficulty in access.

(3) Previous surgeries especially lower abdominal surgeries create a lot of problem during laparoscopic cholecystectomy.

(4) Pus or bile leak creates problem during the surgery because of visual difficulty and surrounding tissue inflammation.

(5) Distended/ contracted gall bladder, structural anomalies, intraperitoneal adhesions creates problem during laparoscopic as well as open cholecystectomy.

\section{References}

[1] McKernan JB, Champion JK. Access techniques: Veress needle - initial blind trocar insertion versus open laparoscopy with the Hasson trocar. Endosc. Surg. Allied Technol. 1995; $3: 35$.

[2] Ballem RV, Rudomanski J. Techniques of pneumoperitoneum. Surg. Laparosc. Endosc. 1993; 3:42.

[3] Alexander JI. Pain after laparoscopy. Br. J. Anaesth. 1997; 79:369.

[4] Rademaker BM, Kalkman CJ, Odoom JA, et al. Intraperitoneal local anaesthetics after laparoscopic cholecystectomy: effects on postoperative pain, metabolic responses and lungfunction.Br.J.Anaesth.1994; 72:263.

[5] LeeIO, KimSH, KongMH, etal. Pain after laparoscopic cholecystectomy: the effect and timing of incisional and intraperitoneal bupivacaine. Can. J. Anaesth. 2001; 48:545.

[6] Murphy JB. The diagnosis of gall stones. Am Med News 1903:825-833.

[7] Hanif G Motiwala: Operative Technique Cholecystectomy A study of 250 Cases: SURGERY IN THE Tropics Ed: Sakens: Jhawes PK: Purohit A Mc Milan India Ltd1991, 56, 204.

[8] Jaskiran S. Randhawa, Aswini K. Pujahari: Preoperative prediction of difficult lap chole: a scoring method, Indian J Surg (July- august 2009) 71:198-201.

[9] Alexander P Nagle, Nathaniel J, Soper James R Hines; Cholecystectomy (open and laparoscopic).Michael J Zinner Stanley W Ashley; Maingot's Abdominal.

[10] Strasburg S M, Hertl M, Soper N S. An analysis of the problem of biliary injury during laparoscopic cholecystectomy. J Ann Coll Surg 1995; 180: 101-125.
[11] Birkett D HRonsky J LStiegmann G V. The SAGES manualFundamentals of Laparoscopic and GI Endoscopy. Springer2003: 137- 142 .

[12] Gupta N, Ranjan G, Arora MP, Binita Goswami, Poras Choudhary, Arun Kapur, et al: Validation of a scoring system to predict difficult laparoscopic cholecystectomy. International Journal of Surgery 2013;11: 1002-1006.

[13] Kama N A, Dogary M, Dolapa M. Reise, Attli M, et al! Risk factors resulting in conversion of laparoscopic cholecystectomy to open cholecystectomy. Surgical endoscopy, Springer New York: V5 965-968.

[14] Daradkeh S laparoscopic cholecystectomy: What are the factors determining difficulty? Hepatogastroenterology. 2001 Jan, Feb; 48(37): 76-78.

[15] Jorgensen J O, Hunt D R: laparoscopic cholecystectomy. A prospective analysis of the potential causes of failure. Surg laparos endosc 3: 49- 531993.

[16] Fried GM, Barkun JS, Sigman HH, Joseph L, Uas D, Garzon J, Hinchey EJ, Meakins JL (1994) Factors determining conversion to laparotomy in patients undergoing laparoscopic cholecystectomy.

[17] Ahmet Alponat, Cheng K, Bee C Koh, Andrea R, Peter MY Goh (1997): Predictive factors for conversion of laparoscopic cholecystectomy. World J Surg 21:629-633. 37.

[18] Kanaan SA, Murayama KM, Merriam LT, Dawes LG, Puystowsky JB, Reye RB, Jochi RJ (2002) Risk factors for conversion of laparoscopic to open cholecystectomy. J Surg Res 106:20-24.

[19] Vivek MA, Augustine AJ, Rao R: A comprehensive predictive scoring method for difficult laparoscopic cholecystectomy. Journal of minimal access surgery. 2014; 10:62-7.

[20] Michael Sugrue, Shaheel M, Sahebally Luca, Ansaloni, martin, D Zielinski: Grading operative findings at laparoscopic cholecystectomy- a new scoring system. World Journal of Emergency Surgery. 2015; 10:14.

[21] Takada T, Strasberg SM, Solomkin JS , Pitt HA, Gomi H, Yoshida M, et al. TG 13 Updated Tokyo guidelines for the management of acute cholangitis and cholecytitis. J Hepatobliary Pacreat Sci. 2013; 20:1-7.

[22] Stromberg C, Nilsson M. Nationwide study of the treatment of common bile duct stones in Sweden between 1965 and 2009. Br J Sirg.2014;98:1766-74.

[23] De Mestral C, Rostein OD, Lapacis A, Hoch JS, Zagorski, Alali A S, et al. Comparative operative outcomes of early and delayed cholecystectomy for acute cholecystitis: a population based propensity score analysis. Ann Surg. 2014; 259:10-5.

[24] Singh Kohri A. Difficult laparoscopic cholecystectomy: a large series from North India. Ind J Surg. 2006; 68:205e208.

[25] Nachnani J Supe A. Pre- operative prediction of difficult laparoscopic cholecystectomy using clinical and ultrasonographic parameters. Indian journal of gastroenterology. 2005; 24:8-16. 